\title{
Current Challenges and Opportunities for Better Integration of Human Factors Research with Development of Clinical Information Systems
}

\author{
J. J. Saleem ${ }^{1-4}$, A. L. Russ ', , P. Sanderson ${ }^{5}$, T. R. Johnson ${ }^{6}$, J. Zhang ${ }^{6}$, D. F. Sittig ${ }^{6,7}$ \\ 'Veterans Affairs Health Services Research \& Development Center on Implementing Evidence-Based \\ Practice, Indianapolis, IN, USA \\ ${ }^{2}$ Indiana University Center for Health Services \& Outcomes Research, Indianapolis, IN, USA \\ ${ }^{3}$ Regenstrief Institute, Indianapolis, IN, USA \\ ${ }^{4}$ Department of Electrical and Computer Engineering, IUPUI, Indianapolis, IN, USA \\ ${ }^{5}$ The University of Queensland and National ICT Australia, St Lucia, QLD, Australia \\ ${ }^{6}$ The University of Texas School of Health Information Sciences, Houston, TX, USA \\ ${ }^{7}$ UT - Memorial Hermann Center for Healthcare Quality \& Safety, Houston, TX, USA
}

\begin{abstract}
Summary
Objectives: Clinical information system (CIS) developers and implementers have begun to look to other scientific disciplines for new methods, tools, and techniques to help them better understand clinicians and their organizational structures, clinical work environments, capabilities of clinical information and communications technology, and the way these structures and processes interact. The goal of this article is to help CIS researchers, developers, implementers, and evaluators better understand the methods, tools, techniques, and literature of the field of human factors. Methods: We developed a framework that explains how six key human factors topics relate to the design, implementation, and evaluation of CISS.

Results: Using this framework we discuss the following six topics: 1) informatics and patient safety; 2) user interface design and evaluation; 3) workflow and task analysis; 4) clinical decision making and decision support; 5) distributed cognition; and 6) mental workload and situation awareness.

Conclusions: Integrating the methods, tools, and lessons learned from each of these six areas of human factors research early in CIS design and incorporating them iteratively during development can improve user performance, user satisfaction, and integration into clinical workflow. Ultimately, this approach will improve clinical information systems and healthcare delivery.

\section{Keywords}

Human factors, clinical information systems, computerized medical record, human information processing, clinical decision support systems

Yearb Med Inform 2009:48-58
\end{abstract}

IMIA Yearbook of Medical Informatics 2009

\section{Introduction}

Recently, there have been several articles in the scientific literature suggesting that simply implementing a stateof-the-art clinical information system (CIS) within the modern healthcare enterprise does not lead to improvements in the quality[1], safety[2] or even cost of healthcare[3]. When these reports are coupled with the increasing pressure on healthcare organizations to provide extensive data describing the quality of care delivered, the pressure on CIS developers and implementers to "get it right" as fast as possible has never been greater. Towards that end, CIS developers and implementers have begun to look outside their expertise to other scientific disciplines for new methods, tools, and techniques to help them better understand the following: clinicians and their organizational structures, clinical work environments, the capabilities of clinical information and communications technology, and how the above structures and processes interact[4].

The goal of this article is to help CIS researchers, developers, implementers, and evaluators better understand the methods, tools, techniques, and literature of the field of human factors. The six areas of current human factors activity within health informatics that we have selected cover the motivation for improving CIS and they provide an overview of current theories, methods, and measurements that are used by human factors within healthcare. Figure 1 provides an overview of these six areas. The caption and the following text explain what the areas represent, and describe how they relate to each other.

The overarching element in Figure 1 is the purpose of CIS, which is to provide information when and where it is needed in order to ensure satisfactory patient outcomes and patient safety. The extent to which CIS supports the demand for information determines whether the system will provide an effective vs. ineffective interface. The form and function of the interface contribute to whether clinical information can be accessed effectively and understood, and whether information can be entered and ordering undertaken with trust in the end result.

The above two factors-the information needed and the form of the interface-influence clinical activities that involve CIS. There are various ways to assess healthcare activities involving CIS: examples from the field of human factors include workflow 


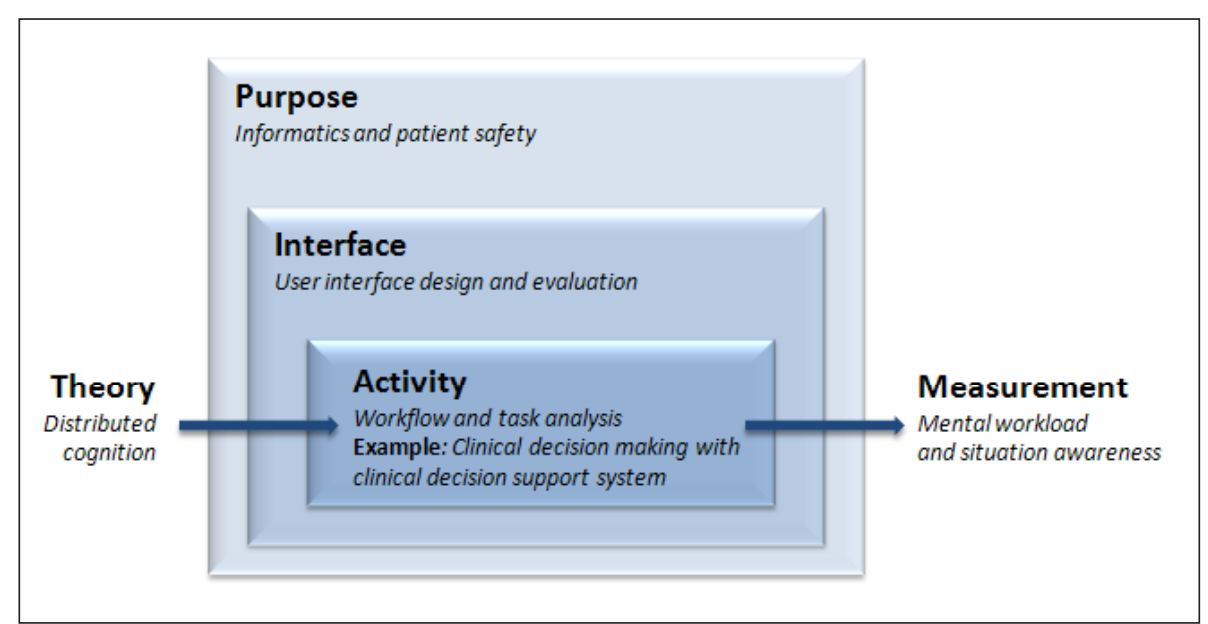

Fig. 1 Framework for the human factors topics presented in this article, as they relate to CIS. The purpose of a CIS is better patient outcomes and greater patient safety. The interface of the CIS can be informed by user-centered design and evaluation methods. Clinician activity can be analyzed with various human factors methods and supported with technology. For example, clinical decision making can be aided with a clinical decision support system. The analysis of activity is guided by theories of activity. Finally, the quality of the cognitive outcomes of activity can also be measured; human factors offers tools to measure the workload that employees experience during CIS use and their awareness of the patient status.

analysis and task analysis. These approaches can help designers better understand how CIS is actually used during clinical work and/or provide information on how CIS can be improved to aid work processes.

There are several work activities that need to be supported by CIS. One key activity is clinical decision-making. This activity may be supported by a clinical decision support system (CDSS) within a CIS. The CDSS may succeed or fail to support clinical decision-making depending upon whether the system interface provides the right information and allows the decisionmaker to access and act upon that information in a manner that supports patient care.

Exactly what constitutes activity, and therefore what needs to be analyzed, is guided by different theoretical viewpoints. An influential viewpoint from human factors that has recently gained interest from health informatics is "distributed cognition"- the idea that cognitive activity is shared amongst different individuals and is spread across time and space.

Finally, CIS design influences the type and quality of interactions health- care employees have with CIS, and also affects employees' cognitive processes and productivity. These human experiences can be strong determinants of whether a clinical information system functions as intended. Two well-researched aspects of human experience are the level of mental workload that a healthcare worker experiences when using a CIS and the degree of situation awareness the clinical information system CIS offers, such as a patient's history, status, and treatment plan.

Although this article does not provide a comprehensive list of human factors topics, it presents some current human factors research topics and outlines opportunities to improve the design and implementation of CISs. Within each topic, we provide a short introduction followed by a brief overview of the key problems in that area; discuss, methods, tools and techniques that can be applied to CIS; and provide resources for additional information. The six topics areas presented in this paper represent key ideas, methods, and tools from human factors, which may be applied to improve CIS design, implementation, and associated patient care.

\section{Purpose: Informatics and Pa- tient Safety}

As shown in Figure 1, a key purpose of informatics is to promote patient safety. Several human factors approaches can help improve the effectiveness of CIS while aiding efforts to reduce the risk of medical harm to patients. Clinical information technology, including the electronic health record (EHR), can be used to enhance patient safety and offers a wide range of novel mechanisms to achieve safety goals. In particular, computerized provider order entry (CPOE) and bar code medication administration (BCMA) have been implemented in hospitals with the intent of reducing the risk of medical harm to patients; research shows that, at least in some cases, these technologies have improved the safety of healthcare in measurable ways [5-7]. Information technologies can potentially aid patient safety by providing enhanced information availability and legibility, clinical decision support; safety alerts for physicians (e.g., medication order checks for drug-drug interactions), and mechanisms such as BCMA to help "double check" clinical procedures that pose greater risk to patients $[5,8]$. These benefits notwithstanding, CIS's potential to enhance patient care and patient safety has not been fully realized in many areas[9]. Moreover, information technologies can have unintended consequences, which may put patients' health at risk and/or lead to medical harm [8, 10-12].

\section{Key Patient Safety Topics for Informatics}

For example, Koppel et al. 2005 found that one CPOE system facilitated 22 types of medication error risks[2]. In a different study, Horsky et al. 2005 analyzed a medication error and concluded that several aspects of $\mathrm{CPOE}$ 
design contributed to a serious, unintentional dosing event [13]. Several other relevant patient safety topics have begun to gain the attention of the informatics and human factors experts: inability to differentiate between truly new information and that which has been cut and pasted in progress notes [10, 14-16]; alert fatigue, i.e., a high frequency of electronic safety alerts leading to desensitization over time $[17,18]$; and informatics over-automation and tight coupling, which can propagate inaccurate information or CIS errors to more healthcare employees more rapidly than traditional paper-based clinical processes $[19,20]$. In addition, information technologies that inadequately support healthcare employees' natural workflow processes are more likely to be associated with workarounds [8, 21]. While some workarounds may appropriately enhance patient safety, others can create unintended risks to patients' well-being $[6,8,22]$. Workarounds have been reported for a variety of clinical informatics technologies including EHRs, CPOE, and BCMA [10, 23-26].

\section{Methods and Tools for Assessing and Improving the Safety of Informatics}

The field of human factors offers several theoretical frameworks and tools to facilitate patient safety goals. One that has received widespread attention in the medical literature, Reason's Swiss cheese model for accident causation, illustrates how different "gaps" can align and lead to patient harm[27]. The more recent Systems Engineering Initiative for Patient Safety (SEIPS) model provides a framework for understanding how work system factors, including informatics technologies, can influence patient safety[4]. Human factors methods and techniques can be used to do the following: 1) prospectively iden- tify potential safety problems with clinical information technology prior to implementation; 2) understand how informatics may promote or hinder patient safety within the context of clinical care and natural workflow processes; and 3) retrospectively evaluate the role of informatics in near misses, adverse events, etc. Table 1 outlines these three general approaches and lists some relevant tools and resources. Additional resources can be found in PubMed and engineering Compendex ${ }^{\circledR}$ literature search databases, the Handbook of Human Factors and Ergonomics in Health Care and Patient Safety, and are available elsewhere [28, 29].

There has been a lot of attention on how CIS can enhance patient safety; certainly, these technologies have much to offer. It is equally important to investigate how CISs may contribute to patient harm and identify what changes need to be made to ensure safer care. To enhance the safety of CISs, mechanisms need to be in place to receive rapid input from employees; prioritize issues related to patient safety; and provide timely responses to employees about how CIS safety issues were actively addressed[21]. If these mechanisms are unreliable or inefficient, then a valuable informatics resource (i.e., employee input) may diminish and, ultimately, patient safety could suffer[30]. Once safety concerns are identified, efforts should be made to address the problem via redesigns of the technology. In human factors, it is well known that removing patient safety hazards through redesigns is a much stronger and effective strategy than relying on warnings, protocols, and training, etc[31]. Human factors practice provides several tools to investigate how informatics influences patient safety. These tools, combined with iterative technology redesigns, can help ensure that information systems promote effective and safe medical care.

Table 1 Three general approaches to informatics and patient safety, their strengths and weaknesses, and corresponding tools and resources. All three of these approaches should be utilized to maximally strengthen patient safery. Some of the more commonly used tools are listed in the right hand column.

\begin{tabular}{|c|c|c|}
\hline Approach & Strengths \& Weaknesses & Tools and Resources \\
\hline Pre-implementation & $\begin{array}{l}\text { - Identifies potential problems before patient harm } \\
\text { occurs; can be rapid; redesigns may promote IT } \\
\text { adoption by employees and minimize workarounds } \\
\text { - Limited ability to predict issues that might occur in } \\
\text { complex, clinical environments }\end{array}$ & $\begin{array}{l}\text { - Usability testing [12,32] } \\
\text { - Heuristic evaluation[33] } \\
\text { - Task analysis [34-36] } \\
\text { - FMEA [37] } \\
\text { - Think aloud } \\
\text { - Cognitive walkthrough }\end{array}$ \\
\hline $\begin{array}{l}\text { Information technology } \\
\text { use in the clinical } \\
\text { context }\end{array}$ & $\begin{array}{l}\text { - Identifies problems that result from complex socio- } \\
\text { technical interactions; reveals how naturally-occurring } \\
\text { workflow issues may influence patient safety } \\
\text { - Some forms of data collection are limited by privacy } \\
\text { restrictions; some methods can be time consuming; } \\
\text { information may be complex to analyze }\end{array}$ & $\begin{array}{l}\text { - Task analysis [34-36] } \\
\text { - FMEA [37] } \\
\text { - Analysis of workarounds and } \\
\text { artifacts [21,25] } \\
\text { - Qualitative approaches: } \\
\text { interviews, direct observations, } \\
\text { focus groups [38] }\end{array}$ \\
\hline $\begin{array}{l}\text { Retrospective analysis of } \\
\text { events (near misses, } \\
\text { ADEs, ADRs, etc) }\end{array}$ & $\begin{array}{l}\text { - Can inform changes to prevent similar, repeat events } \\
\text { - Actual events may be difficult to reconstruct; does nothing } \\
\text { to prevent the initial event from occurring }\end{array}$ & $\begin{array}{l}\text { - Incident report analysis [39] } \\
\text { - Root cause analysis (RCA) [40] }\end{array}$ \\
\hline
\end{tabular}

Abbreviations: ADE - adverse drug event; ADR - adverse drug reaction; FMEA - failure modes and effects analysis 


\section{Interface: User Interface De- sign and Evaluation}

Figure 1 shows that the user interface stands between the broader purpose of the CIS tool and the activity observed. The effectiveness and safety of clinical work processes are significantly shaped and influenced by how the interface is designed. The quality of the interface (e.g., how clear, understandable, and usable it is for employees' work) can determine whether or not healthcare employees accept or reject an attempted CIS implementation. In fact, two of the five major barriers to adoption of healthcare information and communications technology in the U.S. are "lack of userfriendly, integrated technology solutions" and "lack of end-user acceptance" [41]. The CIS that healthcare delivery organizations acquire often fit poorly into actual work practices [42] and, therefore, are deemed inappropriate or unusable by end-users. In one estimate, $75 \%$ of healthcare CIS implementations were considered failures by their users [43].

Even the most motivated end-users in healthcare contexts do not necessarily know how to identify or explain what their information systems should deliver, or how to evaluate potential solutions to their problems [44]. Guidelines about the form that effective user interfaces should take can be difficult to translate into practice, and can even contradict each other $[45,46]$. Following such guidelines does not guarantee effectiveness in rich sociotechnical contexts - a series of papers in health informatics whose titles include the words "unintended consequences" attests to the complexities [8, 10, 47, 48]. In the face of these problems, having an effective process for designing and evaluating the interface between user and system becomes very important.

\section{Key Problems in User Interface Design and Evaluation}

The healthcare industry cycles through enthusiasms for new platforms and ap- plications. The well-known Gartner "hype cycles"[49] reveal a "peak of inflated expectations" and "trough of disillusionment" for emerging healthcare provider applications and systems. If the challenges that new CIS meet in practice could be identified earlier and more accurately, those peaks and troughs could be lessened. User-centered design techniques can help such assessments by providing broad principles (see [50]) to guide the process. Such principles, and challenges for applying them in healthcare, are as follows:

1. Early involvement of end-users and their contexts of use are needed. However, the scale of CIS often makes such involvement difficult [51]. Well-known user-centered design and evaluation methods sometimes do not handle the scale of time and space over which human-system integration takes place in healthcare.

2. System design should be an iterative process with formative (designoriented) and summative (conclusion-oriented) phases of evaluation. Finding the right time to perform such evaluations, and making sure that the results influence development and rollout decisions, are key problems for large-scale CIS projects [52, 53].

3. Progress towards user experience goals should be measured objectively. Deciding upon criteria for the user experience, and finding measures that inform about progress towards those criteria, can be difficult given the scale of CIS applications and the need for a greater focus on safety than in many other contexts $[54,55]$.

\section{Methods and Tools for User Interface Design and Evaluation}

User-centered design and evaluation methods have come to the healthcare industry only relatively recently. Examples of such methods are shown in the first two rows of Table 1. Many papers covering these methods in the peer-reviewed literature are either tutorial in nature $[32,56]$, they recount case studies of applying such methods [57], or both [58, 59]. Nonetheless, taken together, such papers are informative about the wide range of methods and tools available for user interface design and evaluation.

Researchers distinguish between analytic methods, in which evaluations are made on the basis of formal models of interaction or on the basis of expert opinion, and empirical methods, in which evaluations depend on collecting data about user interactions. For example, analytic methods include heuristic evaluation and cognitive walkthroughs, whereas empirical methods include observation of representative users either in the field or in simulated contexts. Researchers are also concerned with different models of end-user participation; these range from strong participatory design methods, where users are also designers, to user testing, where users interact with prototype or production-level systems to reveal design flaws [51]. Healthcare is only slowly starting to be a source of innovation in such methods and tools, often driven by the need to design and evaluate handheld and embedded applications, web-based tools, Radio Frequency Identification (RFID) devices, and so on.

\section{Key Literature and Resources}

General user interface design and evaluation is covered pedagogically by several texts such as Preece et al. (2007) [50] and Benyon et al. (2005) [60]. Bias and Mayhew's (2005) [61] edited volume on cost-justifying usability provides excellent support for those working in the organizational context, and the monograph by Dumas and Redish (1999)[62] provides invaluable support for user testing. Articles cited in the sections above show such methods being used for health applications. Reid et al., (2005) [63] outline how systems engineering and human factors processes might result in better healthcare systems. Fi- 
nally, health-related journals that cover user interface design and evaluation for clinical information systems include Journal of the American Medical Informatics Association, International Journal of Medical Informatics, Journal of Biomedical Informatics, Methods of Information in Medicine, and Quality and Safety in Healthcare.

\section{Activity: Workflow and Task Analysis}

As Figure 1 shows, the system purpose and the CIS interface shape activity. To promote CIS adoption, it is important that its interface and other aspects of its design should support work processes involved in patient care. Work processes can be described and better understood via a family of human factors methods known as workflow analysis[64] and task analysis[65]. With respect to CIS, workflow analysis and task analysis are typically done for either of the following two reasons: 1) to support workflow engineering by introducing changes to how work is accomplished with an existing CIS; or 2) to guide the design of new CIS features or functions that may change workflow and automate tasks. These analyses may be either prescriptive, indicating how work should be done, or descriptive, describing how work is actually done. Workflow analysis generally provides a more global, abstract view of how work moves across various components of a system, such as organizations, committees, people, and equipment. It describes how work is accomplished at each key point in the process. For example, a workflow analysis of an emergency department may indicate that a triage nurse enters triage data in an EHR. In contrast, task analysis usually gives a more detailed description of how each task in a workflow is accomplished. A task analysis would describe the detailed sequence of steps that the nurse needs to take to enter the data into the system.

\section{Methods and Tools to Assess Workflow and Task Analysis}

A number of methods are typically used for workflow and task analysis. For existing work domains or products, descriptive analyses are often performed using methods such as observational (e.g., time-motion) studies, interviews, surveys, and focus groups [64, 65]. For new work domains or products workflow and task analyses require more analytical approaches, but they typically start by addressing the high level goals of the work process, assessing constraints or limitations associated with work processes, and identifying tools that are currently available or must be created to complete the work.

There are several challenges to workflow and task analysis. First, it is often difficult and time consuming to get an accurate characterization of complex sociotechnical systems, such as an intensive care unit (ICU) or Emergency Department (ED). Workflow in such systems tends to emerge from the decisions of each worker as they respond to the highly dynamic demands of the workplace [66]. As a result, no single worker or even manager is likely to know the precise workflow of the entire system, and he or she is rarely completely aware of their own workflow. Interviews with employees or managers often reveal an idealized workflow that is often modified dynamically to work around problems, such as understaffing, missing or damaged equipment, emergency situations, and so on. Observational studies can help reveal these "workarounds" so that they can be incorporated into a more accurate analysis of the work processes. Many difficulties with CISs are due to the fact that designers failed to understand the true workflow, and especially the workarounds, that employees use to get their work done [67]. When a computer-based system, such as an EHR or BCMA, fails to support processes involved in workarounds, patient care can be impeded or completely undermined [23].
Another problem with workflow and task analysis is that they do not separate the work that needs to be done from the specific technology and methods currently available to do the work. They merely describe or analyze how the work is currently being done. An existing workflow is dependent upon the technology that is currently in use to help do the work; if we want to design new and better technology that allows employees to do a better job, we need to understand the hard constraints of the work, independent of the current tools. Work domain analysis (understanding the functional structure of the work context) is one method for doing this [68]. Work domain analysis takes a functional view of the work domain by considering its purpose, operational priorities, domain functions, physical functions, and physical objects or configurations. For instance, the purpose of an ambulance and its crew is to stabilize the patient and transport him or her to an ED, and operational priorities are to do so quickly and safety. The objects in the work domain include the patient's physical location, and the location and status of EDs. These are all important objects in this work domain, regardless of the technology available to help accomplish the primary goals of the domain. Work domain analyses can help us design new technology and workflow processes that allow employees to do their work more safely and efficiently.

A number of tools are available to help with the analyses mentioned above. The Unified Modeling Language (UML) is often used to express workflow diagrams [69]. GOMS (Goal, Operator, Method, Selection) and the Keystroke Level Model (KLM) provide somewhat formal languages for expressing task analyses [70]. Abstraction hierarchies [68] and work domain ontologies [71] are tools for capturing properties of a work domain. Although the use of these techniques is increasing in healthcare, much of the primary literature appears in the fields of human computer interaction (HCI), hu- 
man factors engineering, cognitive engineering, and change management.

\section{Activity Example: Clinical De- cision Making and Decision Support}

Clinical decision making is an example of a clinical activity, as shown in Figure 1 . The field of human factors has an extensive research base involving theories of decision making and how such theories can be applied to CIS design. A person is faced with a decision making task when: 1) s/he must select an option from a number of alternatives; 2) there is some amount of information available with respect to each option; and 3) the choice is associated with some uncertainty [72]. The classic human information processing model describes decision making as spanning three stages: 1) cue reception and integration (e.g., recognition that a decision needs to be made); 2) hypothesis generation and selection; and 3) plan generation and action choice [73]. Decision making models include rational, or "normative", models and descriptive models [72]. Normative models are based on mathematical or statistical models of costs and benefits and represent what the human "should" do assuming that all the input data is available and correct. Descriptive models, such as naturalistic decision making [74], better capture how humans actually make decisions in real-world, complex environments, such as many clinical care situations.

CISs that incorporate well-designed clinical decision support system (CDSS) tools can support cue reception and integration; hypothesis formulation; data analysis and interpretation of information. They can also remind clinicians that a decision must be made at the point-of-care during the clinical decision making process. Well-formatted data displays, embedded calculations, and/or graphical elements can aid the clinician's attempts to understand a patient's current physiologic situation. Likewise, computer algorithms can be developed that improve the clinician's hypothesis formation process. For example, systems such as DxPlain [75], Isabel [76], Illiad [77], and Quick Medical Reference (QMR) [77] were developed specifically to help clinicians formulate a comprehensive differential diagnosis. Likewise, the LDS Hospital in Salt Lake City, UT has developed various applications to help clinicians perform complex data analysis tasks including Evans et al.'s antibiotic advisor [78] and Gardner et al.'s blood gas interpreter [79]. In addition, Sittig et al. created a program that could interpret a patient's current physiological state and use that information to recommend appropriate ventilator settings [80].

All of the CDSS applications described above help clinicians perform better than unaided clinicians in realworld clinical settings. However, the vast majority of CDSS interventions in use today are relatively simple applications whose sole purposes are to double check clinicians' work, alert them about potential mistakes, or let them know that they have forgotten to order a specific test or medication that the patient should be receiving. It has been demonstrated that these simple CDSS tools can improve the quality of care by reducing providers' reliance on memory and by helping clinicians as they attempt to manipulate large, oftentimes conflicting, data sources. In other words, effective tools can support clinicians during their decision making processes.

\section{Key Problems with Decision Making and Decision Support}

Decision making, in all domains, is subject to several human biases in every stage of the process. There are several examples of biases: generation of a limited number of hypotheses due to working memory limitations; cognitive tunneling, where the individual remains stuck in an initial hypothesis; and con- firmation bias, where an individual only seeks confirming information to evaluate a working hypothesis [81]. CDSS can help reduce human biases, improve clinician decision-making, and support adherence with evidence-based guidelines. Ultimately, decision support can improve quality of care[63, 82-85]. However, the use of decision support tools in CISs is quite variable [86-90]. Overall, the implementation of CISs and their integration into clinical workflow has been slow and has not reached its full potential $[88,91]$. This missed opportunity has been caused by inconsistent and incomplete implementation strategies and a failure to use approaches, such as usability testing, to integrate decision support effectively into clinical workflow [85, 88, 92].

\section{Methods and Tools for Developing and Implementing Clinical Decision Support}

CISs can assist clinicians' work by incorporating well-designed decision support systems. Such systems might include computerized clinical reminders, alerts, order checks, templates, complex expert systems, and even simple links to webbased decision support tools and educational information resources. While such technical solutions can have a significant positive impact on clinician's performance, there are still many different sociological or political issues that must be addressed to ensure that these CDSSs are actually used by clinicians.

In an effort to develop methods to address these socio-technical CDSS issues, the Healthcare Information and Management Systems Society (HIMSS) published a guide to CDSS development and implementation that provides six broad steps to consider: 1) identifying CDSS stakeholders and goals; 2) cataloging technical capabilities of available information systems; 3 ) selecting and specifying CDSS interventions; 4) specifying and validating the details, and building the interventions; 5) putting interventions into action (in- 
cluding human factors assessment such as usability testing); and 6) measuring results and refining the clinical decision support tool [93]. Each of these six steps can be accomplished much more effectively if one or more of the human factors theories, tools, and techniques are employed. For example, work domain analysis can be helpful in selecting and specifying CDSS interventions, while careful task analysis studies can be used to identify the best point within the workflow to implement the particular type of CDSS intervention. Measuring and refining the CDSS should include assessing intervention use and usability on an ongoing basis, evaluating the intervention impact on target objectives, and continually enhancing the value of the CDSS to clinicians and its impact on target objectives [93].

In summary, CDSS tools can improve the ability of clinicians to make the right decision, given the right data, at the right point in time, and the right interpretation of the clinical knowledge. In addition to helping CIS developers better understand the underlying decision making process, human factors approaches, such as usability tests and workflow analyses, can also be used as part of the CDSS implementation process and may aid CIS adoption.

\section{Theory: Distributed Cognition}

Figure 1 shows that analyses of user activity can be guided by theories of different kinds. Distributed cognition has recently emerged as a theoretical framework for conducting analyses of human work. Researchers using this approach consider cognition as a system that goes beyond individuals. It is a distributed system approach originally conceptualized by Hutchins and colleagues and later expanded by others [94102]. It has previously been applied to the study of cognitive systems underlying task performance on naval vessels[96] and in the airplane cockpit [97]. Distributed cognition studies show how cognitive activity is distributed across internal human minds, external cognitive artifacts, and groups of people, and how it is distributed across space and time (see Fig. 2) [96-98, 100-107].

Distributed cognition researchers consider people's intelligent behavior to be a result of their interactions with external cognitive artifacts and with other people; people's activities in concrete situations are guided, constrained, and to some extent, determined by the physical, cultural, social, and historical contexts in which they are situated [94, 108]. The unit of analysis is a distributed cognitive system composed of a group of people interacting with external cognitive artifacts (e.g., cockpit of a commercial airplane or the emergency department in a hospital). In general terms, the components of a distributed cognitive system can be described as internal and external representations. Internal representations are the knowledge and structure in individuals' minds; external representations are the knowledge and structure in the external environment [104].
The expression "distributed cognition" does not simply refer to distributed information. Rather, it refers to an architecture through which information is propagated and represented. Furthermore, distributed cognition researchers do not claim that artifacts are cognizing entities. The theory simply models both humans and their artifacts as representational systems. Therefore, distributed cognition is concerned with representations inside and outside the individual's head - and the transformation these structures undergo [109]. The focus is on the representations both internal to the individual and those created and displayed by artifacts [100]. With this viewpoint, distributed cognition researchers can help answer the question, "What information is required to carry out some task and where should it be located, as an interface object [hardware or software] or as something that is mentally represented by the user?" [110]. This type of knowledge is essential for effective CIS design.

Recently, there have been a growing number of studies of healthcare systems from

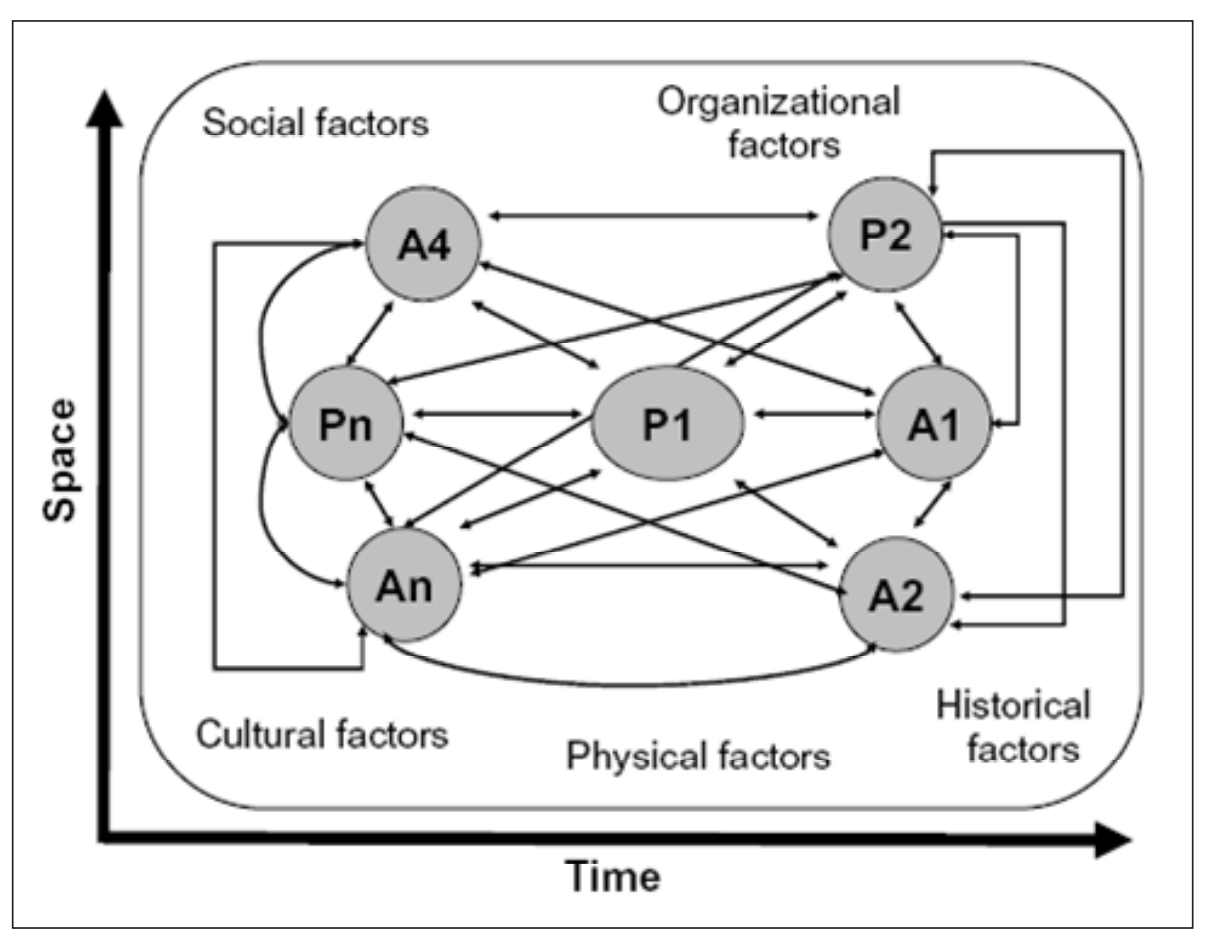

Fig. 2 A conceptual framework of distributed cognition. $P n=$ Person " $n$ "; An $=$ Artifact " $n$ ". This distributed system view shares many ideas with teamwork research in social and behavioral sciences. (From Patel, Zhang, et al., 2008 [108]) 
the distributed cognition perspective [108, 111, 112]. These studies adopted a systems perspective to study the behaviors of complex teams in healthcare settings, such as EDs and ICUs (see [113] for examples). The distributed cognition framework has helped describe, explain, and predict the patterns of healthcare providers' interactions with patients, computer systems, medical devices, and other artifacts in dynamic and complex healthcare settings. New methods, such as RFID tracking and agent based modeling, are now being applied to collect more data about team behavior and test informatics interventions in EDs and ICUs [111, 114]. The preliminary results have shown that these new tools allow researchers to study distributed cognition in ways that were not possible in the past.

\section{Measurement: Mental Work- load and Situation Awareness}

Finally, Figure 1 shows that evaluation is performed via measurement of performance or subjective experience. Mental workload and situation awareness are two fundamental human factors constructs that can inform the development of well-designed CISs. Mental workload is related to the difference between the amount of finite resources (i.e., attention or mental effort) available within a person and the amount of resources demanded by the tasks being performed [73]. If the tasks required by a clinical information system demand excessive attention or mental effort, clinical performance may deteriorate, and the risk of committing an error will increase. Workload refers to the demand that tasks impose on a person's limited resources. Although situation awareness (SA) is correlated with workload [115], they are distinct constructs. Researchers talking of SA make no reference to task demand variables, but they consider nonattentional factors relevant, such as domain knowledge [115]. SA is the perception and comprehension of elements in the environment and the projection of their status in the future [116, 117]; it is a person's internal representation of what is happening. SA drives the decision making process and is a causal factor in human error. There are several types of SA: geographical, spatial, temporal, system, and environmental.

\section{Key Problems with Workload and Situation Awareness}

CISs should be designed so that clinicians can use them during the most complex tasks, with reasonable mental workload, and while maintaining situation awareness. If mental processing demands exceed available resource capacity, performance degradation will begin to occur, which may lead to errors while using the clinical information system. SA is an important framework from which to draw when designing a clinical work environment, such as an EHR-enabled exam room. A properly designed work environment will present the necessary information at the appropriate time, without requiring the clinician to divert his or her attention away from the patient. As with excessive mental workload, a reduction in one or more types of SA may lead to a deterioration of clinical performance and result in human error. Workload and SA should be considered together during the development and evaluation of a clinical information system since they are intimately linked constructs. For example, designing more automated functions in a CIS may reduce the workload of a clinician. However, the same automated functions may also reduce the clinician's SA unless appropriate feedback is designed into the human-computer interface to keep the clinician in the loop.

\section{Methods and Tools to Assess Workload and Situation Awareness}

Measures of mental workload are typically classified as performance measures, physiological measures, and sub- jective measures [73, 118]. Subjective measures have been perhaps most commonly used to assess workload of CISs. The NASA Task Load Index (TLX) is one of the most popular subjective workload assessment scales in human factors research [119]. The NASA TLX scale can be used to assess perceived workload across several dimensions (e.g., mental demand, effort, frustration). The scale has been validated as being sensitive to detect changes in perceived workload across varying levels of task difficulty [120]. It has been used in several domains to assess workload in complex environments, including for the evaluation of CISs, such as a pulmonary display [121] and computerized clinical reminders [122].

Evaluation of situation awareness in healthcare environments has been gaining popularity. For example, SA has recently been applied to healthcare research as a guide to a better understanding of diagnostic errors in medicine [123]. The Situation Awareness Global Assessment Technique (SAGAT) is perhaps the most widely used measure of $\mathrm{SA}$, originally developed to measure pilot SA in aviation [124]. SAGAT provides an objective measure of SA using simulated scenarios that are halted at random times. SAGAT has been adapted for use in healthcare to assess practical trauma skills for medical training [125] and could be readily adapted for use in evaluating CISs in a simulated environment or usability laboratory [126].

\section{Key Literature for Workload and Situation Awareness}

Most of the literature on mental workload and SA is not indexed in Medline, because these human factors constructs were predominately developed and refined in psychology and engineering fields. Therefore, databases such as PsycINFO and Compendex ${ }^{\circledR}$ are relevant places to search for this key literature, where many of the references in this section were obtained from, in combination with Medline / Pubmed. 
In addition, the Handbook of Human Factors and Ergonomics [127] gives a comprehensive overview of this topic, with the latest material and references.

\section{Summary}

Human factors research and methods should be routinely used to support the design of CISs prior to implementation and also throughout the implementation of these complex systems. Adopting human factors input early and iteratively into CIS development can improve user performance, usability, and CIS integration into clinical workflow. Human factors can also reduce costs by addressing important human-computer interaction considerations pre-implementation, where redesign costs are much less than those post-implementation.

In this paper, we outlined some current opportunities for better integration of human factors in the development of CISs, covering six key topic areas: informatics and patient safety; user interface design and evaluation; workflow and task analysis; clinical decision making and decision support; distributed cognition; and mental workload and situation awareness. An overarching theme of these six areas is to help CIS designers better understand human cognition, as well as interactional capabilities and limitations of clinicians involved in performing clinical tasks involving CISs.

With this human factors design framework, technology does not drive work processes; rather, technological tools are designed with appropriate input from individuals working in the clinical environment. We strongly believe that such a human factors approach can engage clinicians in CIS design, help designers better incorporate the cognitive demands of clinical work tasks, and ultimately help improve clinical work processes and patient safety. The overall goal of this work is to better align the clinical workflow facilitated by the CISs with the required patient care tasks to improve the safety and efficiency of the healthcare delivery system.

\section{Acknowledgments}

This work was supported in part by the US Department of Veterans Affairs (VA), VA HSR\&D Center of Excellence on Implementing Evidence-Based Practice (CIEBP), HSR\&D Center grant \#HFP 04-148. A VA HSR\&D Associated Health Postdoctoral Fellowship supported Dr. Russ. The views expressed in this article are those of the authors and do not necessarily represent the view of the US Department of Veterans Affairs. National ICT Australia is funded through the Australian Government's Backing Australia's Ability initiative in part through the Australian Research Council. Dr. Sittig was funded in part by a research grant from the National Library of Medicine R56LM006942. We thank Wendy Broxham for help in literature review.

\section{References}

1. Linder JA, Ma J, Bates DW, Middleton B, Stafford RS. Electronic health record use and the quality of ambulatory care in the United States. Arch Intern Med 2007;167(13):1400-5.

2. Koppel R, Metlay JP, Cohen A, Abaluck B, Localio AR, Kimmel SE, et al. Role of computerized physician order entry systems in facilitating medication errors. JAMA 2005;293(10):1197-203.

3. Congressional Budget Office: Evidence on the Costs and Benefits of Health Information Technology; May 2008 Available at: http://www.cbo.gov/ftpdocs/ 91xx/doc9168/05-20-HealthIT.pdf.

4. Carayon P, Schoofs HA, Karsh BT, Gurses AP, Alvarado CJ, Smith M, et al. Work system design for patient safety: the SEIPS model. Qual Saf Health Care 2006;15 Suppl 1:i50-i58.

5. Cochran GL, Jones KJ, Brockman J, Skinner A, Hicks RW. Errors prevented by and associated with bar-code medication administration systems. Jt Comm J Qual Patient Saf. 2007 May;33(5):293301, 245.

6. Morriss FH, Jr. Effectiveness of a Barcode Medication Administration System in Reducing Preventable Adverse Drug Events in a Neonatal Intensive Care Unit: A Prospective Cohort Study. 2008.

7. Ammenwerth E, Schnell-Inderst P, Machan C, Siebert U. The Effect of Electronic Prescribing on Medication Errors and Adverse Drug Events: A Systematic Review. J Am Med Inform Assoc
2008;15(5):585-600.

8. Ash JS, Berg M, Coiera E. Some unintended consequences of information technology in health care: the nature of patient care information system-related errors. J Am Med Inform Assoc 2004 MarApr;11(2):104-12.

9. Bates DW, Gawande AA. Improving safety with information technology. N Engl J Med 2003;348(25):2526-34.

10. Campbell EM, Sittig DF, Ash JS, Guappone KP, Dykstra RH. Types of unintended consequences related to computerized provider order entry. J Am Med Inform Assoc 2006;13(5):547-56.

11. Weiner JP, Kfuri T, Chan K, Fowles JB. "eIatrogenesis": the most critical unintended consequence of $\mathrm{CPOE}$ and other HIT. J Am Med Inform Assoc 2007;14(3):387-88.

12. Zhang J, Patel VL, Johnson TR, Shortliffe EH: A cognitive taxonomy of medical errors. J Biomed Inform 2004:37(3):193-204.

13. Horsky J, Kuperman GJ, Patel VL. Comprehensive analysis of a medication dosing error related to CPOE J Am Med Inform Assoc 2005;12(4):377-82.

14. Hammond KW, Helbig ST, Benson CC, BrathwaiteSketoe BM. Are electronic medical records trustworthy? Observations on copying, pasting and duplication. AMIA Annu Symp Proc 2003:269-73.

15. Hartzband P, Groopman J. Off the record-avoiding the pitfalls of going electronic. N Engl J Med 2008;358(16):1656-8.

16. Weir CR, Hurdle JF, Felgar MA, Hoffman JM, Roth B, Nebeker JR. Direct text entry in electronic progress notes. An evaluation of input errors. Methods Inf Med 2003;42(1):61-7.

17. Glassman PA, Belperio P, Simon B, Lanto A, Lee M. Exposure to automated drug alerts over time: effects on clinicians' knowledge and perceptions. Med Care 2006;44(3):250-6.

18. van der Sijs H, Aarts J, Vulto A, Berg M. Overriding of drug safety alerts in computerized physician order entry. J Am Med Inform Assoc 2006;13(2):138-47.

19. Cook RI, Woods DD. Implications of automation surprises in aviation for the future of total intravenous anesthesia (TIVA). J Clin Anesth 1996;8(3 Suppl):29S-37S.

20. Sarter NB, Woods DD, Billings C.E. Automation Surprises. In Handbook of Human Factors and Ergonomics. Edited by G.Salvendy: Wiley; 1997.

21. Karsh BT, Holden RJ, Alper SJ, Or CK. A human factors engineering paradigm for patient safety: designing to support the performance of the healthcare professional. Qual Saf Health Care 2006;15 Suppl 1:i59-i65.

22. Amalberti R, Vincent C, Auroy Y, de Saint MG. Violations and migrations in health care: a framework for understanding and management. Qual Saf Health Care 2006;15 Suppl 1:i66-i71

23. Koppel R, Wetterneck T, Telles JL, Karsh BT. Workarounds to barcode medication administration systems: their occurrences, causes, and threats to patient safety. J Am Med Inform Assoc 2008;15(4):408-23.

24. Niazkhani Z. Evaluating the impact of CPOE systems on medical workflow: a mixed method study. Stud Health Technol Inform 2008;136:881-2.

25. Saleem JJ, Russ AL, Justice CF, Hagg H, Ebright PR, Woodbridge PA, et al. Exploring the persistence of paper with the electronic health record. Int 
$\mathrm{J}$ Med Inform, in press.

26. Unertl KM, Weinger MB, Johnson KB: Applying direct observation to model workflow and assess adoption. AMIA Annu Symp Proc 2006:794-8.

27. Reason J. Beyond the organisational accident: the need for "error wisdom" on the frontline. Qual Saf Health Care 2004, 13 Suppl 2:ii28-ii33.

28. Handbook of Human Factors and Ergonomics in Health Care and Patient Safety. Mahwah, NJ: Lawrence Erlbaum Associates; 2007.

29. Walker JM, Carayon P, Leveson N, Paulus RA, Tooker J, Chin H, et al. EHR safety: the way forward to safe and effective systems. J Am Med Inform Assoc 2008;15(3):272-7.

30. Tucker AL, Edmondson AC. Why Hospitals Don't Learn from Failures: Organizational and Psychological Dynamics that Inhibit System Change. California Management Review 2003;45(2):55-72.

31. Render ML. Research and redesign are safer than warnings and rules. Crit Care Med 2004; 32(4):1074-5

32. Kushniruk AW, Patel VL. Cognitive and usability engineering methods for the evaluation of clinical information systems. J Biomed Inform 2004 37(1):56-76.

33. Zhang J, Johnson TR, Patel VL, Paige DL, Kubose T. Using usability heuristics to evaluate patient safety of medical devices. J Biomed Inform 2003;36(1-2):23-30.

34. Chung PH, Zhang J, Johnson TR, Patel VL. An extended hierarchical task analysis for error prediction in medical devices. AMIA Annu Symp Proc 2003:165-9.

35. Kirwan B, Ainsworth LK: A Guide to Task Analysis. Bristol, PA: Taylor \& Francis, Inc.; 1992.

36. Lane R, Stanton NA, Harrison D. Applying hierarchical task analysis to medication administration errors. Appl Ergon 2006;37(5):669-79.

37. DeRosier J, Stalhandske E, Bagian JP, Nudell T. Using health care Failure Mode and Effect Analysis: the VA National Center for Patient Safety's prospective risk analysis system. Jt Comm J Qual Improv 2002;28(5):248-67, 209

38. Ash JS, Sittig DF, McMullen CK, Guappone K, Dykstra R, Carpenter J. A rapid assessment process for clinical informatics interventions. AMIA Annu Symp Proc 2008:26-30.

39. Zhan C, Hicks RW, Blanchette CM, Keyes MA, Cousins DD. Potential benefits and problems with computerized prescriber order entry: analysis of a voluntary medication error-reporting database. Am J Health Syst Pharm 2006;63(4):353-8.

40. Gosbee J, Anderson T. Human factors engineering design demonstrations can enlighten your RCA team. Qual Saf Health Care 2003;12(2):119-21.

41. Eastwood G. ICT opportunities in healthcare. In: Business Insights, London; 2005.163 pp.

42. Han YY, Carcillo JA, Venkataraman ST, Clark RS, Watson RS, Nguyen TC, et al. Unexpected increased mortality after implementation of a commercially sold computerized physician order entry system. Pediatrics 2005;116(6):1506-12.

43. Littlejohns P, Wyatt JC, Garvican L. Evaluating computerised health information systems: hard lessons still to be learnt. BMJ 2003; 326(7394):860-3.

44. Schulman J, Kuperman GJ, Kharbanda A, Kaushal R. Discovering how to think about a hospital patient information system by struggling to evaluate it: a committee's journal. J Am Med Inform Assoc 2007;14(5):537-41

45. Myers B. Challenges of HCI design and implementation. Interactions 1994;1(1):73-83.

46. Burmester M, Machate J. Creative design of interactive products and use of usability guidelines-A contradiction? In: Jacko JA, Stephanidis C, Harris D, Mahwah NJ, editors. Human-computer interaction: Theory and practice. NJ: Lawrence Erlbaum Associates; 2003.

47. Ash JS, Sittig DF, Poon EG, Guappone K, Campbell E, Dykstra RH. The extent and importance of unintended consequences related to computerized provider order entry. J Am Med Inform Assoc 2007; 14(4):415-23.

48. Harrison MI, Koppel R, Bar-Lev S. Unintended consequences of information technologies in health care-an interactive sociotechnical analysis. J Am Med Inform Assoc 2007; 14(5):542-9.

49. Runyon B, Handler T, Hieb B, Shaffer V, Jonathan E, Lovelock JD, et al. Hype cycle for healthcare provider applications and systems. In: Gartner Industry Report ID Number G00148329 edition. Stamford, CT: Gartner Inc.; 2007.

50. Preece J, Sharp H, Rogers Y. Interaction Design; Beyond human-computer interaction (2nd edition). New York: Wiley; 2007

51. Pilemalm S, Timpka T. Third generation participatory design in health informatics - making user participation applicable to large-scale information system projects. J Biomed Inform 2008;41(2):327-39.

52. McGowan JJ, Cusack CM, Poon EG. Formative evaluation: a critical component in EHR implementation. J Am Med Inform Assoc 2008;15(3):297-301.

53. Westbrook JI, Braithwaite J, Georgiou A, Ampt A, Creswick N, Coiera E, et al. Multimethod evaluation of information and communication technologies in health in the context of wicked problems and sociotechnical theory. J Am Med Inform Assoc 2007;14(6):746-55.

54. Karsh BT. Beyond usability: designing effective technology implementation systems to promote patient safety. Qual SafHealth Care 2004;13(5):388-94

55 . Liljegren E. Usability in a medical technology context assessment of methods for usability evaluation of medical equipment. International Journal of Industrial Ergonomics 2006;36:345-52

56. Jaspers MW. A comparison of usability methods for testing interactive health technologies: methodological aspects and empirical evidence. Int J Med Inform 2009;78(5):340-53.

57. Peute LW, Jaspers MW. The significance of a usability evaluation of an emerging laboratory order entry system. Int J Med Inform 2007;76(2-3):157-68.

58. Bernonville S, Kolski C, Leroy N, Beuscart-Zephir MC. Integrating the SE and HCI models in the human factors engineering cycle for re-engineering Computerized Physician Order Entry systems for medications: Basic principles illustrated by a case study. Int J Med Inform. In press 2008.

59. Johnson CM, Johnson TR, Zhang J. A user-centered framework for redesigning health care interfaces. J Biomed Inform 2005;38(1):75-87.

60. Benyon D, Turner P, Turner S. Designing interactive systems: People, activities, contexts. Harlow, UK: Addison-Wesley; 2005.

61. Bias R, Mayhew D. Cost-justifying usability: An update in the internet age. New York: Morgan-
Kaufmann; 2005.

62. Dumas J, Redish J. A practical guide to usability testing. Intellect; 1999.

63. Reid PP, Compton D, Grossman JH, Fanjiang G. Committee on Engineering and the Health Care System. Building a better delivery system: A new engineering/health care partnership. In: Washington, D.C.: National Academies Press; 2005.

64. Sharp A, McDermott P. Workflow Modeling: Tools for Process Improvement and Application Development, 2nd Edition. Artech House Publishers; 2008.

65. Hackos JTP, Redish JC. User and Task Analysis for Interface Design. 1st ed. Wiley; 1998.

66. Hazlehurst B, McMullen C, Gorman P, Sittig D. How the ICU follows orders: care delivery as a complex activity system. AMIA Annu Symp Proc 2003:284-8.

67. Sittig DF, Ash JS, Zhang J, Osheroff JA, Shabot MM. Lessons from "Unexpected increased mortality after implementation of a commercially sold computerized physician order entry system". Pediatrics 2006;118(2):797-801.

68. Vicente KJ: Cognitive Work Analysis. Lawrence Erlbaum Associates; 1999.

69. Booch G, Rumbaugh J, Jacobson I. Unified Modeling Language User Guide, The 2nd Edition. Addison-Wesley Professional; 2005.

70. Card SK, Moran TP, Newell A. The Psychology of Human-Computer Interaction. Hillsdale, NJ: L. Erlbaum Associates, Inc.; 1983.

71. Butler KA, Zhang J, Esposito C, Bahrami A, Hebron $\mathrm{R}$, Kieras D. Work-centered design: a case study of a mixed-initiative scheduler. In: Proceedings of the SIGCHI conference on Human factors in computing systems, San Jose, CA; 2007. p. 747-56.

72. Wickens CD, Lee JD, Liu Y, Gordon Becker SE. An Introduction to Human Factors Engineering. 2nd Ed. Upper Saddle River, NJ: Pearson Prentice Hall; 2004.

73. Wickens CD. Engineering Psychology and Human Performance 2nd Ed. New York, NY: HarperCollins Publishers, Inc.; 1992.

74. Zsambok CE, Klein G. Naturalistic Decision Making. Mahwaw, NJ: Erlbaum; 1997.

75. Barnett GO, Cimino JJ, Hupp JA, Hoffer EP. DXplain. An evolving diagnostic decision-support system. JAMA 1987;258(1):67-74.

76. Graber ML, Mathew A. Performance of a web-based clinical diagnosis support system for internists. J Gen Intern Med 2008;23 Suppl 1:37-40.

77. Friedman CP, Elstein AS, Wolf FM, Murphy GC, Franz TM, Heckerling PS, et al. Enhancement of clinicians' diagnostic reasoning by computer-based consultation: a multisite study of 2 systems. JAMA 1999:282(19):1851-6

78. Evans RS, Pestotnik SL, Classen DC, Clemmer TP, Weaver LK, Orme JF Jr, et al. A computerassisted management program for antibiotics and other antiinfective agents. N Engl J Med 1998;338(4):232-8

79. Gardner RM, Cannon GH, Morris AH, Olsen KR, Price WG. Computerized Blood Gas Interpretation and Reporting System. Computer 1975;8(1):39-45.

80. Sittig DF, Pace NL, Gardner RM, Beck E, Morris AH. Implementation of a computerized patient advice system using the HELP clinical information system. Comput Biomed Res 1989;22(5):474-87.

81. Groopman JE. How Doctors Think. Boston: Houghton-Mifflin; 2007. 
82. Bates DW, Pappius E, Kuperman GJ, Sittig D, Burstin H, Fairchild D, et al. Using information systems to measure and improve quality. Int J Med Inform 1999;53(2-3):115-24.

83. Bates DW, Teich JM, Lee J, Seger D, Kuperman GJ, Ma'Luf N, et al. The impact of computerized physician order entry on medication error prevention. J Am Med Inform Assoc 1999;6(4):313-21.

84. Bates DW, Cohen M, Leape LL, Overhage JM, Shabot MM, Sheridan T. Reducing the frequency of errors in medicine using information technology. J Am Med Inform Assoc 2001;8(4):299-308

85. Doebbeling BN, Chou AF, Tierney WM. Priorities and strategies for the implementation of integrated informatics and communications technology to improve evidence-based practice. J Gen Intern Med 2006;21 Suppl 2:S50-S57.

86. Agrawal A, Mayo-Smith MF. Adherence to computerized clinical reminders in a large healthcare delivery network. Stud Health Technol Inform 2004;107(Pt 1):111-4.

87. Demakis JG, Beauchamp C, Cull WL, Denwood R, Eisen SA, Lofgren R, et al. Improving residents' compliance with standards of ambulatory care: results from the VA Cooperative Study on Computerized Reminders. JAMA 2000;284(11):1411-6.

88. Garg AX, Adhikari NK, McDonald H, Rosas-Arellano MP, Devereaux PJ, Beyene J, et al. Effects of computerized clinical decision support systems on practitioner performance and patient outcomes: a systematic review. JAMA 2005;293(10):1223-38

89. Sequist TD, Gandhi TK, Karson AS, Fiskio JM, Bugbee D, Sperling M, et al. A randomized trial of electronic clinical reminders to improve quality of care for diabetes and coronary artery disease. J Am Med Inform Assoc 2005;12(4):431-7.

90. Shea S, DuMouchel W, Bahamonde L. A metaanalysis of 16 randomized controlled trials to evaluate computer-based clinical reminder systems for preventive care in the ambulatory setting. J Am Med Inform Assoc 1996;3(6):399-409.

91. Osheroff JA, Teich JM, Middleton B, Steen EB, Wright A, Detmer DE. A roadmap for national action on clinical decision support. J Am Med Inform Assoc 2007;14(2):141-5.

92. Snyder-Halpern R. Indicators of organizational readiness for clinical information technology/systems innovation: a Delphi study. Int J Med Inform 2001;63(3):179-204

93. Osheroff JA, Pifer EA, Teich JM, Sittig DA, Jenders RA. Improving Outcomes with Clinical Decision Support: An Implementer's Guide. Chicago: HIMSS; 2005.

94. Dror IE, Harnad S. Cognition Distributed. Amsterdam: John Benjamins Publishing Company; 2008

95. Hollan J, Hutchins E, Kirsh D. Distributed cognition: toward a new foundation for human-computer interaction. ACM Transactions on Computer-Human Interaction 2000;7(2):174-96.

96. Hutchins E. Cognition in the wild. Cambridge, MA: MIT Press; 1995

97. Hutchins E. How a cockpit remembers its speed. Cognitive Science 1995;19:265-88.

98. Norman DA. Cognitive artifacts. In Designing inter- action: Psychology at the human-computer interface. New York: Cambridge University Press; 1991.

99. Rogers Y, Ellis J. Distributed cognition: an alternative framework for analysing and explaining collaborative working. Journal of Information Technology 1994;9:119-28

100. Zhang J, Norman DA. Representations in distributed cognitive tasks. Cognitive Science 1994;18(1):87-122.

101. Zhang J. Distributed representation as a principle for the analysis of cockpit information displays. International Journal of Aviation Psychology 1997;7:105-21.

102. Zhang J. A distributed representation approach to group problem solving. Journal of American Society of Information Science 1998;49(9):801-9.

103. Patel VL, Kaufman DR, Allen VG, Shortliffe EH, Cimino JJ, Greenes RA. Toward a framework for computer-mediated collaborative design in medical informatics. Methods Inf Med 1999:38(3):158-76

104. Patel VL, Cytryn KN, Shortliffe EH, Safran C. The collaborative health care team: the role of individual and group expertise. Teach Learn Med 2000;12(3):117-32

105. Suchman L. Plans and situated actions: The problem of human-machine communication. New York: Cambridge University Press; 1987.

106. Wegner DM. Transactive memory: A contemporary analysis of the group mind. In: Mullen B, Goethals GR, editors. Theories of group behavior. New York: Springer-Verlag; 1987.

107. Zhang J. The nature of external representations in problem solving. Cognitive Science 1997;21:179-217.

108. Patel VL, Zhang J, Yoskowitz NA, Green R, Sayan OR. Translational cognition for decision support in critical care environments: a review. J Biomed Inform 2008;41(3):413-31.

109. Nardi BA. Studying context: a comparison of activity theory, situated action models, and distributed cognition. In: Nardi BA, editor. Context and Consciousness: Activity Theory and HumanComputer Interaction. Cambridge, MA: MIT Press; 1996:69-102.

110. Wright PC, Fields RE, Harrison MD. Analyzing human-computer interaction as distributed cognition: the resources model. Human-Computer Interaction 2000;15:1-41.

111. Cohen T, Blatter B, Almeida C, Shortliffe E, Patel VL. A cognitive blueprint of collaboration in context: distributed cognition in the psychiatric emergency department. Artif Intell Med 2006;37(2):73-83.

112. Hazlehurst B, Gorman PN, McMullen CK. Distributed cognition: an alternative model of cognition for medical informatics. Int J Med Inform 2008;77(4):226-34.

113. Xiao Y. Artifacts and collaborative work in healthcare: methodological, theoretical, and technological implications of the tangible. J Biomed Inform 2005;38(1):26-33

114. Patel V, Zhang J. Distributed cognition in critical care. 2009, Personal Communication.

115. Selcon SJ, Taylor RM, Koritsas E. Workload or situation awareness? TLX vs. SART for aerospace systems design evaluation. In: Proceeding of the Human Factors Society 35th Annual Meeting 1991; Santa Monica, CA; 1991. p. 62-6.

116. Endsley MR. Design and evaluation for situation awareness enhancement. In: Proceedings of the Human Factors Society 32nd Annual Meeting 1988; Santa Monica, CA; 1988. p. 97-101

117. Endsley MR. Situation Awareness. In: Salvendy G, editor. Handbook of Human Factors, 3rd Ed. Hoboken, NJ: John Wiley \& Sons, Inc; 2006:528-42.

118. Tsang P, Wilson GF. Mental Workload. In Salvendy G, editor. Handbook of Human Factors, 2nd Ed. New York: John Wiley \& Sons; 1997:417-49.

119. NASA Task Load Index (TLX) for Windows Available at: http://www.nrl.navy.mil/aic/ide/ NASATLX.php. Accessed on: April 27, 2009.

120. Hart S, Staveland L. Development of the NASATLX (Task Load Index): Results of empirical and theoretical research. In: Hancock PA, Meshkati $\mathrm{N}$, editors. Human Mental Workload. North-Holland: Elsevier Science Publishers; 1988:139-83.

121. Wachter SB, Johnson K, Albert R, Syroid N, Drews F, Westenskow D. The evaluation of a pulmonary display to detect adverse respiratory events using high resolution human simulator. J Am Med Inform Assoc 2006;13(6):635-42.

122. Saleem JJ, Patterson ES, Militello L, Anders S, Falciglia M, Wissman JA, et al. Impact of clinica reminder redesign on learnability, efficiency, usability, and workload for ambulatory clinic nurses. J Am Med Inform Assoc 2007; 14(5):632-40.

123. Singh H, Petersen LA, Thomas EJ. Understanding diagnostic errors in medicine: a lesson from aviation. Qual Saf Health Care 2006;15(3):159-64

124. Endsley MR, Selcon SJ, Hardiman TD, Croft DG. A comparative analysis of SAGAT and SART for evaluations of situation awareness. In: Proceedings of the Human Factors \& Ergonomics Society 42nd Annual Meeting 1998; Santa Monica, CA; 1998. p. 82-6.

125. Hogan MP, Pace DE, Hapgood J, Boone DC. Use of human patient simulation and the situation awareness global assessment technique in practical trauma skills assessment. J Trauma 2006;61(5):1047-52.

126. Wright MC, Taekman JM, Endsley MR. Objective measures of situation awareness in a simulated medical environment. Qual Saf Health Care 2004;13 Suppl 1:165-i71.

127. Handbook of Human Factors, 3rd Ed. Wiley \& Sons, Inc.; 2006

\section{Correspondence to:}

Dean F. Sittig

UT-Memorial Hermann Center for Healthcare Quality and Safety

6410 Fannin St. UTPB 1100.43

Houston, TX 77030,

USA

Tel: + 17135007977

Fax: +1 7135000766

E-mail: Dean.F.Sittig@uth.tmc.edu 